www.jmscr.igmpublication.org

Impact Factor (SJIF): 6.379

Index Copernicus Value: 71.58

ISSN (e)-2347-176x ISSN (p) 2455-0450

crossref DOI: https://dx.doi.org/10.18535/jmscr/v6i5.175

Journal Of Medical Science And Clinical Research

IGM Publication

An Official Publication of IGM Publication

\title{
Antepartum Oligohydramnios and Perinatal Outcome: A Reevaluation
}

\author{
Authors
}

\section{Dr Sabahat Rasool MS, MRCOG (UK), DNB, MNAMS, FMAS ${ }^{1}$, Dr Tamkin Rabbani (MD, DNB, MNAMS, MICOG) ${ }^{2}$, Dr Omar S Akhtar (MS, DNB (Surgery), MRCS (Edin), DNB (Urology), FMAS) ${ }^{3}$, Prof Nazoora Khan (MD) ${ }^{4}$, Prof Ibne Ahmad (MD) ${ }^{5}$, Dr Nishat Afroz (MD) ${ }^{6}$}

${ }^{1}$ Fertility Consultant\& Reproductive Medicine Specialist, Gynaecworld, Mumbai

${ }^{2}$ Professor, Department of Obstetrics and Gynecology, Jawaharlal Nehru Medical College, Aligarh Muslim

University, Aligarh

${ }^{3}$ Lecturer in Urology, Government Medical College, Srinagar, J\&K

${ }^{4}$ Professor, Dept of Pathology, Jawaharlal Nehru Medical College, Aligarh Muslim University, Aligarh ${ }^{5}$ Professor, Dept of Radiodiagnosis, Jawaharlal Nehru Medical College, Aligarh Muslim University, Aligarh

${ }^{6}$ Lecturer, Dept of Pathology, Jawaharlal Nehru Medical College, Aligarh Muslim University, Aligarh Corresponding Author

\section{Sabahat Rasool}

Fertility Consultant \& Reproductive Medicine Specialist, Gynaecworld, Mumbai, India

Email: sabahatrasool@yahoo.co.in, Mob: 08879337870

\begin{abstract}
Objective: The study was undertaken to re-evaluate the impact of isolated oligohydramnios on pregnancy and perinatal outcome.

Study Design: The study was a case-control study of 100 antenatal subjects in the Department of Obstetrics and Gynaecology in collaboration with Departments of Pathology and Radio-diagnosis, Jawaharlal Nehru Medical College, AMU, Aligarh, India over a period of two years (2012-2015). Two groups, study and control, based on their latest amniotic fluid assessment, were evaluated to determine the relationship between amniotic fluid index (AFI) and gestational age at delivery, induction of labour, meconium-stained liquor, cesarean delivery, birth weight, congenital anomalies, Apgar Score at 5 minutes and neonatal complications. Statistical evaluation was done using z-test. Subjects and controls were matched for age, social status and gravidity.

Results: AFI determinations in 100 pregnant females beyond 34 weeks gestation were used to allocate the patients to the study (AFI $<5 \mathrm{~cm}$, oligohydramnios) and the control (AFI 5-25cm) groups.

The mean gestational age at delivery was significantly lower in the study group. Labour was induced in a significantly higher number of patients in the study group compared to the control group. The incidence of cesarean delivery and congenital anomalies was significantly higher in the study group. There was no statistically significant difference in meconium-staining of liquor, birth weights, low 5-minute Apgar Score and neonatal complications between the two groups.

Conclusion: Oligohydramnios has been classically considered an indicator of fetal compromise and compromised utero-placental circulation but recent studies have called this into question. The present study suggests that the benefits of AFI in ante-partum surveillance need to be re-determined in a large, multi-center, randomised study.
\end{abstract}




\section{Introduction}

Oligohydramnios, defined as an amniotic fluid index (AFI) of less than $5 \mathrm{~cm}$ (standard definition $)^{1}$, complicates 0.5 to $8 \%$ pregnancies. $^{2}$ AFI is calculated by summing up the maximum vertical pockets of amniotic fluid in each quadrant of uterus using Phelan's method. ${ }^{3}$ Oligohydramnios has been associated with poor pregnancy outcome but some recent studies have shown different results. ${ }^{4-7}$ To reevaluate the relationship between oligohydramnios and perinatal outcome, a prospective case-control study was done in the author's institution, a tertiary-care hospital at Aligarh.

\section{Materials and Methods}

The study was carried out on 100 antenatal cases over a period of two years, with their consent. Approval was taken from the Institutional Ethics Committee. AFI determinations, according to Phelan's method, were done using 2-4 MHz sector and linear array transducers, using Siemens Sonoline Adara and GE model RT 3200 machines. The study group consisted of 40 females with singleton pregnancies beyond 34 weeks gestation with the latest AFI of less than $5 \mathrm{~cm}$ (isolated oligohydramnios), without any other pregnancy complications.

The control group consisted of 60 females with singleton pregnancy beyond 34 weeks gestation with the latest AFI between 5 and $25 \mathrm{~cm}$.

No cases with ruptured membranes, abnormal presentations, gestation beyond 40 weeks or with other pregnancy complications like PIH, GDM, etc were included. Cases were followed till delivery. Cases with abnormal Doppler studies were excluded from the study. Correlations were made between AFI and parameters like gestational age at delivery, induction of labour, meconium-inliquor, mode of delivery, birth weight, congenital anomalies, poor Apgar Score and neonatal complications.

\section{Results}

Perinatal outcome was correlated with the latest AFI and comparison was made between the study and the control groups.

Table I compares gestational age at delivery, labor induction, meconium staining and caesarean delivery rates between the study and the control groups.

Table I: AFI \& Labor Outcome

\begin{tabular}{|l|c|c|c|}
\hline Parameter & AFI $<\mathbf{5 c m}(\mathbf{n}=\mathbf{4 0})$ & AFI 5-25cm $(\mathbf{n}=\mathbf{6 0})$ & p Value \\
\hline $\begin{array}{l}\text { Gestational age at } \\
\text { delivery (weeks) }\end{array}$ & $36.5 \pm 2.1$ & $38.1 \pm 1.9$ & $<0.001$ \\
\hline Labor induction & $38(95 \%)$ & $17(28.3 \%)$ & $<0.001$ \\
\hline Meconium staining & $10(25 \%)$ & $11(18.3 \%)$ & $>0.5$ \\
\hline Cesarean delivery & $21(52.5 \%)$ & $18(30 \%)$ & $<0.05$ \\
\hline
\end{tabular}

The gestational age at delivery was significantly lower in the study group $(p<0.001)$.Labor was induced in significantly higher number of patients in the study group (95\%) compared to the control group (28.3\%).

There was no statistically significant difference in the incidence of meconium in liquor between the two groups. Meconium-in-liquor was assessed either after spontaneous or artificial membrane rupture.

As shown in Table I, more number of cases in the study group were delivered by cesarean section as compared to that in the control group $(\mathrm{p}<0.05)$. The most common indications for cesarean section in the study group were fetal distress $47.6 \%$, followed by cervical dystocia in $28.5 \%$, whereas the most common indications in the control group were dystocia, $44.4 \%$, followed by fetal distress, $16.7 \%$. Fetal distress was defined as abnormal fetal heart rate on auscultation or cardiotocogram, not correctable by simple measures, like left lateral position, oxygen inhalation and discontinuation of uterotonics. 
Table II: AFI \& Perinatal Outcome

\begin{tabular}{|l|c|c|c|}
\hline Parameters & $\begin{array}{c}\text { AFI }<\mathbf{5 c m} \\
(\mathbf{n = 4 0})\end{array}$ & $\begin{array}{c}\text { AFI 5-25cm } \\
(\mathbf{n = 6 0})\end{array}$ & p Value \\
\hline Birth weight (grams) & $2300 \pm 500$ & $2760 \pm 450$ & $>0.5$ \\
\hline Congenital anomalies & $06(15 \%)$ & $01(1.7 \%)$ & $<0.05$ \\
\hline Apgar score $<7$ at 5 min & $06(15 \%)$ & $05(8.3 \%)$ & $>0.5$ \\
\hline Neonatal complications & $06(15 \%)$ & $05(8.3 \%)$ & $>0.5$ \\
\hline
\end{tabular}

Table II compares the birth weights, congenital anomalies, Apgar score at 5 minutes and neonatal complications between the study and the control groups. The mean birth weight of neonates was $2300 \pm 500$ grams in the study group and $2760 \pm$ 450 grams in the control group, the difference being statistically insignificant. The apparent difference in the birth weights could be attributed to the difference in the gestational ages at delivery. As shown in Table II, there were significantly more anomalies in the study group (15\%) than in the control group (1.7\%). The anomalies in the study group included Infantile Polycystic Kidney Disease (PCKD), 02, omphalocele with pinna amputation and talipo-equino-varus, 01, Down's Syndrome with hypoplastic kidneys, 01, absent urinary bladder, 01 and anencephaly, 01. Hypoplastic kidneys, PCKD and absent urinary bladder lead to oligohydramnios due to decreased urine production. Anencephaly and omphalocele are classically linked with polyhydramnios due to excessive transudation of the body fluids through the exposed membranes.

Low Apgar Score at 5 minutes was observed in 15\% cases in the study group and $8.3 \%$ cases in the control group, making the difference statistically insignificant.

Neonatal complications like sepsis, seizures, meconium aspiration syndrome were present in $15 \%$ cases in the study group and $8.3 \%$ cases in the control group. Statistically, there was no significant difference in the occurrence of neonatal complications between the two groups.

\section{Discussion}

Ultrasonographic assessment of AFI is used frequently to identify at-risk fetuses antenatally. Oligohydramnios is linked with pulmonary hypoplasia, fetal distress, cord-compression, and increased perinatal morbidity and mortality. ${ }^{8,9}$

In the present study, with respect to perinatal outcome, there was an association between oligohydramnios and lower gestational age at delivery, increased induction of labour, caesarean delivery and congenital anomalies.

Lower gestational age at delivery was because of early induction in the oligohydramnios group, the sole indication for induction being the diagnosis of oligohydramnios per-se. This result is consistent with Locatelli et al, who reported that a significantly higher number of patients with oligohydramnios were induced compared to those with normal AFI. ${ }^{10}$

A higher rate of cesarean deliveries in our study group could be explained on the basis of very high induction rates (95\% vs $28.3 \%$ ) compared to the control group. Fetal distress was the most common indication for caesarean in the study group. However, fetal distress could not be confirmed objectively because of non-availability of scalp pH and arterial blood gas analysis.

A meta-analysis done by Suneet P Chauhan et al found that an antepartum AFI $\leq 5 \mathrm{~cm}$, in comparison with AFI $>5 \mathrm{~cm}$, was associated with an increased risk of caesarean delivery. ${ }^{11}$

A high rate of fetal anomalies was observed in the oligohydramnios group, suggesting a need of detailed fetal anomaly- scan whenever oligohydramnios is detected.

Statistically, there were no differences in meconium staining of liquor, birth weights, low Apgar Score at 5 minutes and neonatal complications between the two groups.

Locatelli et al also reported no difference in meconium staining of liquor between the oligohydramnios and the normal groups. 
However, Alchalabi et al, ${ }^{12}$ Brain M Casey et al ${ }^{13}$ reported a higher incidence of meconium staining in the oligohydramnios group. This discrepancy could be explained because of the inclusion of other risk factors in their studies, namely postdated gestations, hypertensive disorders, diabetes, etc.

William $\mathbf{J}$ Ott reported similar results as ours when comparing the birth weights between the AFI groups. ${ }^{14} \mathrm{He}$ also found no differences in Apgar Scores at $5 \mathrm{~min}$ and occurrence of neonatal complications between the oligohydramnios and the normal groups, the results being similar to ours. $^{14}$

Alchalabi et al, on the contrary, reported significant difference in Apgar Scores of oligohydramnios and normal groups.

Assessment of AFI is an essential and heavily weighted parameter of fetal surveillance. Oligohydramnios has been classically considered an indicator of fetal compromise and compromised utero-placental circulation but recent studies have concluded otherwise. Kreiser et al did not find a poor perinatal outcome in cases of isolated oligohydramnios ${ }^{5}$ William $\mathrm{J}$ Ott concluded that oligohydramnios was a rather weak predictor of perinatal outcome. ${ }^{14}$ Magann et al studied 1001 patients and concluded that high risk pregnancies with an AFI $\leq 5 \mathrm{~cm}$ appear to carry intrapartum complication rates similar to those of high risk pregnancies with an AFI $>5 \mathrm{~cm} .{ }^{15} \mathrm{~A}$ meta-analysis done by Suneet $\mathrm{P}$ Chauhan et al found that an antepartum AFI $\leq 5 \mathrm{~cm}$, in comparison with AFI $>5 \mathrm{~cm}$, is associated with an increased risk of caesarean delivery for fetal distress and low Apgar Score at 5 minutes. ${ }^{11}$

\section{Conclusion}

The present study suggests that the benefits of AFI in ante-partum surveillance need to be redetermined in a large, multi-center, randomised study.

\section{References}

1. American College of Obstetricians and Gynecologists. Antepartum fetal surveillance. Practice Bulletin No. 9 : Antepartum fetal surveillance. October 1999.

2. Peipert JF, Donnenfeld AE. Oligohydramnios: A Review. Obstet Gynecol Surv. 1999;46:325.

3. Rutherford SE, Phelan JP, Smith DV, Jacobs N. The four quadrant assessment of $\mathrm{AFV}$; an adjunct to fetal heart rate testing. Obstet gynecol. 1987;70:353.

4. Garmel SH, Chelmow D, Sha SJ, Roan JT, D'Alton ME. Oligohydramnios and appropriately grown fetus. Am J Perinat 1997;14:359-63.

5. Kreiser D, EI-Sayed YY, Sorem KA, Chitkara U, Holbrook RH, Druzin ML. Decreased amniotic fluid in low risk pregnancy. J Reprod Med 2001;46:743-6.

6. Magann EF, Chauhan SP, Doherty DA, Barrilleuax PS, Martin JN, Morrison JC. Predictability of intrapartum and neonatal outcomes with the amniotic fluid volume distribution: a reassessment using the amniotic fluid index, single deepest pocket, and a dye-determined amniotic fluid volume. Am J Obstet Gynecol 2003;188:1523-8.

7. Magann EF, Kinsella MJ, Chauhan SP, McNamara MF, Gehring BW, Morrison JC. Does an amniotic fluid index of less than $5 \mathrm{~cm}$ necessitate delivery in high-risk pregnancies? A case-control study. Am J ObstetGynecol1999;180:1354-9.

8. Shipp TD, Bromley B, Panker S. Outcome of singleton pregnancies with severe oligohydramnios in second and third trimesters. Ultrasound Obstet Gynecol 1996;7:108.

9. Bastide A, Manning F, Harman C. Ultrasound evaluation of amniotic fluid: outcome of pregnancies with severe oligohydramnios. Am J Obstet Gynecol 1986;154:895. 
10. Locatelli A, Vergani P, Toso L, Verderio M, Pezzullo JC, Ghidini A. Perinatal outcome associated with oligohydramnios in uncomplicated term pregnancies. Arch GynecolObstet 2004; 269:130-33.

11. Chauhan SP, Sanderson M, Hendrix NW, Magann EF, Devoe LD. Perinatal outcome and amniotic fluid index in antepartum and intrapartum periods: a meta-analysis. Am J ObstetGynecol1999;181:1473-8.

12. Alchalabi HA, Obeidat BR, Jallad MF, Khader YS. Induction of labor and perinatal outcome: the impact of AFI. Eur J Obstet Gynecol Reprod Biol 2005.

13. Casey BM, McIntire DD, Bloom SL, Lucas MJ, Santos R, Twickler DM, Ramus RM, Leveno KJ. Pregnancy outcomes after antepartum diagnosis of oligohydramnios at or beyond 34 weeks gestation. Am J ObstetGynecol2000;182:909-12.

14. Ott WJ. Reevaluation of the relationship between amniotic fluid volume and perinatal outcome. Am J Obstet Gynecol 2005;192:1803-9.

15. Magann EF, Chauhan SP, Kinsella MJ, McNamara MF, Whitworth NS, Morrison JC. Antenatal testing among 1001 highrisk patients: the role of ultrasonographic estimation of amniotic fluid volume. Am J ObstetGynecol1999;180:1330-6. 